\title{
Spinal ventral epidural arteriovenous fistulas of the lumbar spine: angioarchitecture and endovascular treatment
}

\author{
Hiro Kiyosue • Shuichi Tanoue • Mika Okahara • \\ Yuzo Hori • Junji Kashiwagi • Hiromu Mori
}

Received: 19 November 2012 / Accepted: 11 December 2012 / Published online: 11 January 2013

(C) The Author(s) 2013. This article is published with open access at Springerlink.com

\begin{abstract}
Introduction Spinal ventral epidural arteriovenous fistulas (EDAVFs) are relatively rare spinal vascular lesions. We investigated the angioarchitecture of spinal ventral EDAVFs and show the results of endovascular treatment.

Methods We reviewed six consecutive patients (four males and two females; mean age, 67.3 years) with spinal ventral EDAVFs treated at our institutions from May 2011 to October 2012. All patients presented with progressive myelopathy. The findings of angiography, including 3D/2D reformatted images, treatments, and outcomes, were investigated. A literature review focused on the angioarchitecture and treatment of spinal ventral EDAVFs is also presented. Results The EDAVFs were located in the ventral epidural space at the L1-L5 levels. All EDAVFs were supplied by the dorsal somatic branches from multiple segmental arteries. The ventral somatic branches and the radiculomeningeal arteries also supplied the AVFs in two patients. The AVFs drained via an epidural venous pouch into the perimedullary vein in four patients and into both the perimedullary vein and paravertebral veins in two patients. Four cases without paravertebral drainage were treated by transarterial embolization with diluted glue, and two cases with perimedullary and paravertebral drainages were treated by transvenous embolization alone or in combination with transarterial embolization. An
\end{abstract}

H. Kiyosue $(\triangle) \cdot$ S. Tanoue $\cdot$ M. Okahara $\cdot$ J. Kashiwagi $\cdot$

H. Mori

Department of Radiology, Oita University Faculty of Medicine,

1-1 Idaigaoka, Hasama,

Yufu City, Oita, Japan 879-5593

e-mail: hkiyosue@med.oita-u.ac.jp

Y. Hori

Department of Radiology, Nagatomi Neurosurgical Hospital,

1-1 Idaigaoka, Hasama,

Yufu City, Oita, Japan 879-5593 angiographic cure was obtained in all patients. Clinical symptoms resolved in two patients, markedly improved in three patients, and minimally improved in one patient.

Conclusion In our limited experience, spinal ventral EDAVFs were primarily fed by somatic branches. EDAVFs can be successfully treated by endovascular techniques selected based on the drainage type of the AVF.

Keywords Spinal artery · Arteriovenous fistula · Embolization $\cdot$ Spinal vein $\cdot$ Arteriovenous malformation

\section{Introduction}

Spinal ventral epidural arteriovenous fistulas (EDAVFs) are relatively rare spinal vascular lesions, and they are generally thought to present with benign clinical symptoms, such as radiculopathy $[1,2]$. However, cases showing progressive myelopathy with spinal venous drainage have been reported [3]. Although spinal ventral EDAVFs have been treated by several techniques, including surgery, transarterial embolization, transvenous embolization, and combinations of these techniques, a treatment strategy based on their angiographic features is not well established [3-22]. In this study, we investigated the angioarchitecture of spinal ventral EDAVFs and the results of endovascular treatment at our institutions. A review of the literature focusing on the angiographic findings and treatment strategies are also presented.

Vascular anatomy relevant to spinal EDAVFs and anatomical terms used in this article are demonstrated on Fig. 1. The dorsal somatic branches originate from a segmental artery at the intervertebral foramen separately from the radiculomeningeal artery and run transversely in the ventral epidural space with anastomoses with their contralateral counterparts at the midline and with the ascending/descending somatic branches of the caudate/cranial segmental arteries. The ventral somatic branches originate from the main trunk of the segmental 


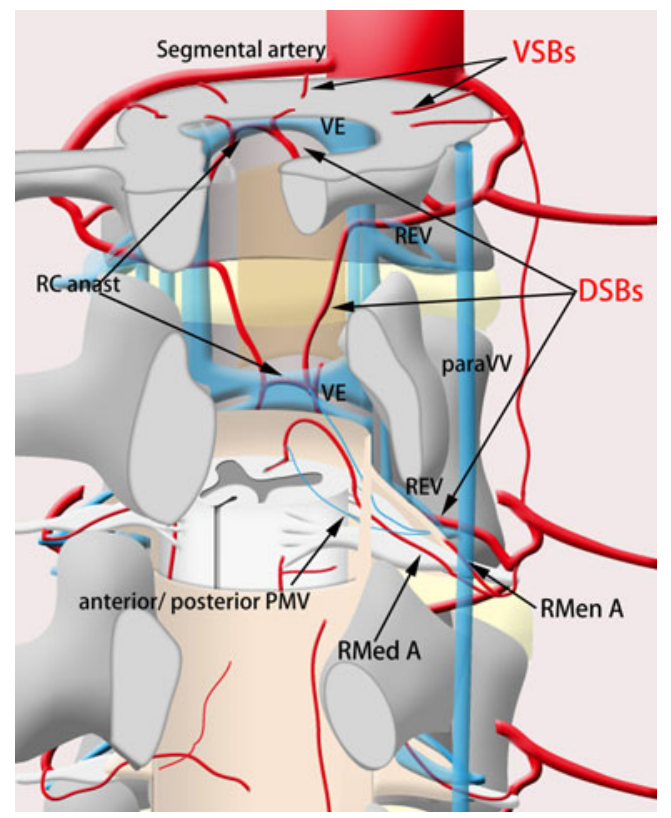

Fig. 1 Schematic drawing of the spinal vascular anatomy relevant to ventral epidural arteriovenous fistula. VSBS, ventral somatic branches; $D S B s$, dorsal somatic branches; RMen A, radiculomeningeal artery; $R M e d A$, radiculomedullary artery; $R C$ anast, retrocorporal anastomosis; $V E$, ventral epidural venous plexus; para $V V$, paravertebral vein; $R E V$, radiculoemissary vein; $P M V$, perimedullary vein

artery, and penetrate into the vertebral body. These somatic branches supply the vertebral body.

\section{Materials and methods}

We reviewed six consecutive patients with spinal ventral EDAVFs treated at our institutions from May 2011 to October 2012. The clinical findings of the six patients are summarized in Table 1. There were four males and two females, and the age ranged from 60 to 82 years (mean age, 67.3 years). All patients presented with progressive myelopathy with varying degrees of paresthesia $(n=5)$ and lower extremity muscle weakness $(n=6)$ and rectobladder dysfunction $(n=4)$. The duration of the symptoms ranged from 3 months to 6 years. Two patients were initially
Fig. 2 Case 2: a, b Sagittal T2-weighted MR images of the spine show a hyperintensity at the conus medullaris and dilated vessels at the posterior surface of the spinal cord (white arrowheads in a). A signal void (white arrow in b) suggesting a shunted pouch is seen in the ventral epidural space at L3. c, d Selective angiography of the left (c) and right (R) third lumbar arteries shows epidural AVFs fed by dorsal somatic branches (white arrows). The ventral somatic branch (arrowheads in d) of the right third lumbar artery also feeds the AVF. The AVFs drain into an epidural venous pouch, then into the ascending lumber vein and the left radiculomedullary vein to the perimedullary vein (arrows). e Axial reformatted images of rotational angiography of the right third lumbar artery demonstrates the AVF with a shunted venous pouch (S) fed by the ventral somatic branch (white arrowheads) and dorsal somatic branch (large white arrows). The shunted venous pouch is located at the mid-portion of the ventral epidural space and runs leftward laterally then continues to the radiculomedullary-perimedullary vein (small white arrows) and runs inferiorly to the ascending lumbar vein. f Selective angiography of the left third lumbar artery during selective transvenous embolization shows coils placed into the shunted venous pouch. g Selective angiography of the left third lumbar artery after embolization shows disappearance of the AVFs

diagnosed with lumber disc herniation, and one patient had been followed for 6 years with a diagnosis of demyelinating disease of the spinal cord. All patients underwent MRI with a 1.5T MR (EXCELART Vantage, Toshiba Medical, Tokyo, Japan). Selective angiography was also performed, including biplane angiography and rotational angiography of the feeding segmental arteries using biplane angiography (Innova3131, GE Medical Systems, Milwaukee; Infinix VB, Toshiba Medical, Tokyo). The rotational angle was $200^{\circ}$, and the rotational speed of the C-arm was $40^{\circ} / \mathrm{s}$ (Innova3131) or $50 \%$ s (Infinix VB). Data were acquired in a $512 \times 512$ matrix using an 8 -in. field-of-view flat panel detector. A nonionic iodinated contrast material (iopamidol, Iopamiron 300; Bayel HealthCare Japan, Osaka, Japan) was injected intraarterially at a flow rate of $1.2-2 \mathrm{~mL} / \mathrm{s}(8.4$ $14 \mathrm{~mL}$ of the total volume) through an automatic injector, and the injection was initiated $1.5 \mathrm{~s}$ before the rotation. Each patient gave written informed consent for angiography and interventional procedures before the examinations. Threedimensional images with a maximum intensity projection as

Table 1 Symptoms and duration of symptoms of patients

\begin{tabular}{llll}
\hline & Age/gender & Duration of symptoms & Symptoms \\
\hline 1 & $60 \mathrm{M}$ & 10 months & Progressive paresthesia and muscle weakness of both legs $\left(\mathrm{MMT}_{4}\right)$ \\
2 & $60 \mathrm{M}$ & 5 months & Progressive paresthesia and muscle weakness of both legs $\left(\mathrm{MMT}_{4}\right)$, rectobladder dysfunction \\
3 & $69 \mathrm{M}$ & 3 months & Progressive paresthesia and muscle weakness of both legs $\left(\mathrm{MMT}_{3}\right)$, rectobladder dysfunction \\
4 & $73 \mathrm{~F}$ & 4 months & Progressive paresthesia paraplegia $\left(\mathrm{MMT}_{1}\right)$, rectobladder dysfunction \\
5 & $60 \mathrm{M}$ & 6 years & Progressive paresthesia paraplegia $\left(\mathrm{MMT}_{1}\right)$, rectobladder dysfunction \\
6 & $82 \mathrm{~F}$ & 3 months & Progressive paresthesia $\left(\mathrm{MMT}_{3}\right)$ \\
\hline
\end{tabular}



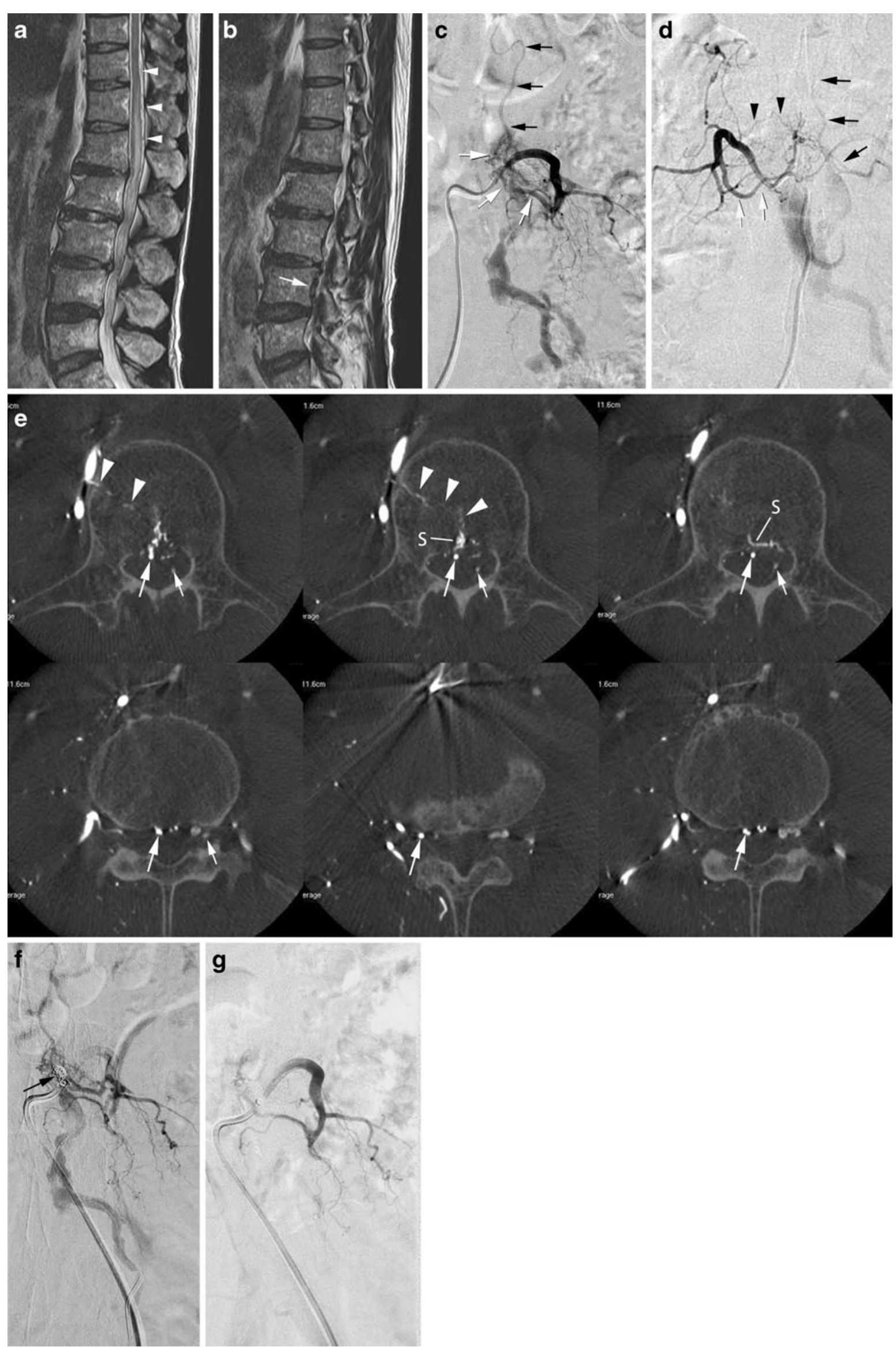

g 
well as MPR images of the consequence composed of slices with 0.3 - to $1-\mathrm{mm}$ thickness and $0.5-\mathrm{mm}$ intervals were obtained from rotational angiography data using a workstation. All 2D angiographic images and MPR images were reviewed by two experienced neuroradiologists (H.K. and S.T.) to reach a consensus regarding the feeding arteries, location of the shunted pouch, and draining veins. Interventional procedures, angiographical outcomes, complications, and clinical outcomes were also evaluated.

Institutional review board approval is not required for this type of retrospective review study at our institution.

\section{Results}

MRI revealed a hyperintensity in the spinal cord involving the conus medullaris and dilatation of the perimedullary veins in all patients. A dilated flow void was found in the ventral epidural space in three patients (Fig. 2). Angiographic findings are summarized in Table 2. The EDAVFs were located in the ventral epidural space with a shunted pouch at L1-L5 levels. Multiple feeders from segmental arteries, including the intercostal artery, the lumbar artery, and the iliolumbar artery, fed the EDAVFs multisegmentally and/or bilaterally, which converged to the shunted pouch with multiple shunting points in all patients. The dorsal somatic branches of these segmental arteries were found to mainly supply the AVFs in all patients (Figs. 2 and 4).
Transvertebral supply from ventral somatic branches to the AVF was observed in two patients (Fig. 2e). The radiculomeningeal arteries also fed the AVFs in two patients (Fig. 4e). The AVFs drained through the epidural venous pouch retrogradely into the radiculomedullary and perimedullary veins in four patients (Figs. 3 and 4). In the other two patients, the AVFs drained through the epidural venous pouch into the perimedullary vein and also into the paravertebral vein (the azygous vein and the ascending lumber vein) through the radiculoemissary vein (Fig. 2). These angiographic findings were clearly demonstrated by MIP and MPR images from rotational angiography. CT and MPR images from rotational angiography showed bone erosion of the vertebral body adjacent to the shunted venous pouch in two patients.

All six patients were treated by transcatheter embolization. Four cases without paravertebral drainage were treated by transarterial embolization with diluted glue (17-20\% $n$-butyl-2-cyanoacrylate-lipiodol mixture) using a dual catheter technique with bilateral femoral arterial approaches. Using the shepherd hook-shaped $4 \mathrm{~F}$ guiding sheath, a 1.5-1.7 $\mathrm{F}$ microcatheter was selectively introduced into the main feeding artery of the dorsal somatic branch just proximal to the fistulous portion, and another microcatheter was placed into the feeder arising from the contralateral side or another segmental level. Diluted glue was slowly injected via the main feeder simultaneously with the slow injection of $5 \%$ glucose via another microcatheter to avoid early

Table 2 Angioarchitechtures and results of the treatments

\begin{tabular}{|c|c|c|c|c|c|c|c|c|}
\hline & $\begin{array}{l}\text { Locations of } \\
\text { shunted pouch }\end{array}$ & $\begin{array}{l}\text { Feeding artery segmental } \\
\text { artery/branch }\end{array}$ & Drainage & $\begin{array}{l}\text { Bone } \\
\text { erosion }\end{array}$ & $\begin{array}{l}\text { Treatment } \\
\text { (materials) }\end{array}$ & $\begin{array}{l}\text { Angiographic } \\
\text { results }\end{array}$ & Complications & $\begin{array}{l}\text { Clinical outcome } \\
\text { (follow-up months) }\end{array}$ \\
\hline 1 & $\begin{array}{r}\text { L1 (ventrolateral } \\
\text { epidural space) }\end{array}$ & $\begin{array}{l}\text { It L1, rt L1, It th12/ } \\
\text { ventral and dorsal } \\
\text { somatic brs, } \\
\text { radiculomeningeal } \\
\text { branches }\end{array}$ & $\begin{array}{l}\text { PMV PVV } \\
\text { (AZV, } \\
\text { LtRV) }\end{array}$ & Yes & $\begin{array}{l}\text { TVE (coils) } \\
\text { and TAE } \\
(17-20 \% \\
\text { NBCA) }\end{array}$ & Cure & $\begin{array}{l}\text { Radiation } \\
\text { dermatitis }\end{array}$ & $\begin{array}{l}\text { Residual mild } \\
\text { paresthesia of the } \\
\text { left thigh (12) }\end{array}$ \\
\hline 2 & $\begin{array}{l}\text { L3 (ventrocentral } \\
\text { epidural space) }\end{array}$ & $\begin{array}{l}\text { It L3, rt L3/ventral and } \\
\text { dorsal somatic } \\
\text { branches }\end{array}$ & $\begin{array}{l}\text { PMV PVV } \\
\text { (ALV) }\end{array}$ & Yes & TVE (coils) & Cure & No & No symptoms (12) \\
\hline 3 & $\begin{array}{c}\text { L4 (ventrocentral } \\
\text { epidural space) }\end{array}$ & $\begin{array}{l}\text { It L4, rt L4 dorsal } \\
\text { somatic branches }\end{array}$ & PMV & No & $\begin{array}{l}\text { TAE }(20 \% \\
\text { NBCA })\end{array}$ & Cure & No & $\begin{array}{l}\text { Residual mild } \\
\text { paresthesia of the } \\
\text { right foot (11) }\end{array}$ \\
\hline 4 & $\begin{array}{l}\text { L5 (ventrocentral } \\
\text { epidural space) }\end{array}$ & $\begin{array}{l}\text { It ILA, rt ILA/ dorsal } \\
\text { somatic branches }\end{array}$ & PMV & No & $\begin{array}{l}\text { TAE }(20 \% \\
\text { NBCA })\end{array}$ & Cure & No & $\begin{array}{l}\text { Residual mild leg } \\
\text { weakness (12) }\end{array}$ \\
\hline 5 & $\begin{array}{c}\text { L5 (ventrocentral } \\
\text { epidural space) }\end{array}$ & $\begin{array}{l}\text { It ILA, rt ILA, rt L4/ } \\
\text { dorsal somatic branch, } \\
\text { radiculomeningeal } \\
\text { branch }\end{array}$ & PMV & No & $\begin{array}{l}\text { TAE }(20 \% \\
\text { NBCA })\end{array}$ & Cure & No & $\begin{array}{l}\text { Residual paresthesia } \\
\text { and leg weakness } \\
\text { (3) }\end{array}$ \\
\hline 6 & $\begin{array}{l}\text { L2 (ventrocentral } \\
\text { epidural space) }\end{array}$ & $\begin{array}{r}\text { Lt L2, rt L2/dorsal } \\
\text { somatic branches }\end{array}$ & PMV & No & $\begin{array}{l}\text { TAE }(17 \% \\
\text { NBCA })\end{array}$ & Cure & No & No symptoms (1) \\
\hline
\end{tabular}

$P M V$ perimedullary vein, $P V V$ paravertebral vein, $A Z V$ azygous vein, $R V$ renal vein, $A L V$ ascending lumber vein, $T V E$ transvenous embolization, TAE transarterial embolization 

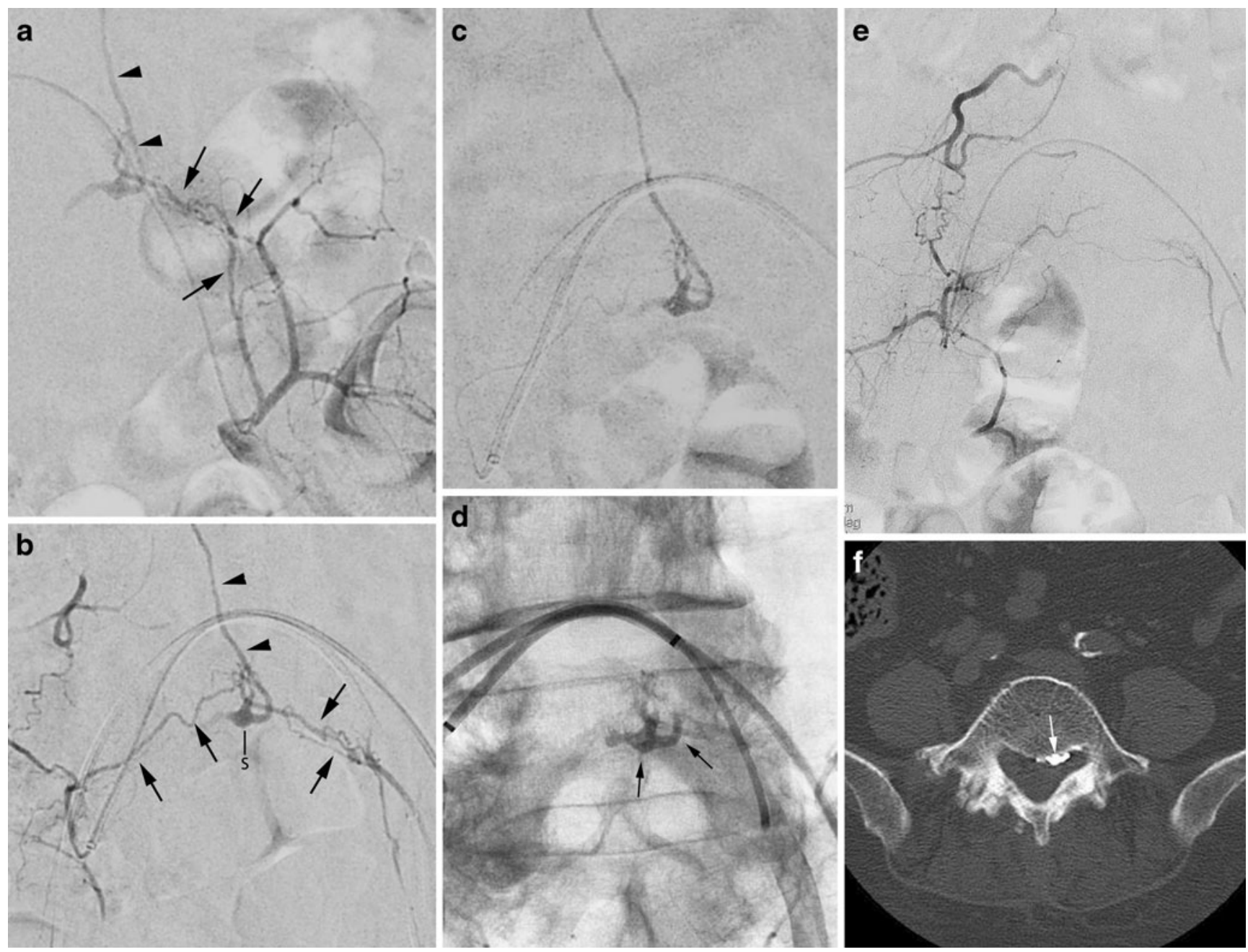

Fig. 3 Case 4: a Selective angiography of the left iliolumbar artery shows epidural AVFs fed by the dorsal somatic branches (arrows). The AVFs drain into an epidural venous pouch, then into the left radiculomedullary vein and to the perimedullary vein (arrowheads). b Selective angiography with simultaneous injection of contrast media via the two microcatheters placed into the bilateral dorsal somatic branches clearly shows the bilateral dorsal somatic branches (arrows) feed the AVF with a shunted venous pouch $(S)$ at the midline. The AVF drains into the radiculomedullary-perimedullary vein (arrowheads). c Selective angiography with contrast injection via a microcatheter placed

polymerization and fragmentation of the glue (Figs. 3 and 4). In all four cases, the EDAVFs disappeared immediately with sufficient filling of the glue in the shunted pouch and partially in the radiculomedullary vein. The other two cases, with intradural and paravertebral drainage, were treated by transvenous embolization with coils (Fig. 2). A $1.9 \mathrm{~F}$ microcatheter was advanced coaxially into the shunted venous pouch through a $4 / 6 \mathrm{~F}$ coaxial guiding catheter system by a right femoral venous approach. Then, coils were selectively placed into the shunted pouch. In one case, the AVFs disappeared after a single transvenous embolization. In the other case, closed to the fistulous point from the right iliolumbar artery. A diluted glue (20\% NBCA-lipiodol mixture) was injected via the microcatheter with simultaneous injection of $20 \%$ glucose via another microcatheter placed at the left dorsal somatic branch of the left iliolumbar artery. d Fluoroscopic image immediately after embolization shows sufficient filling of the glue cast (arrows) in the shunted pouch and the proximal portion of the radicullomedullary vein. e Selective angiography of the right iliolumbar artery after embolization shows disappearance of the AVFs. f CT after embolization shows glue cast in the ventral epidural pouch

small residual AVFs remained after selective transvenous embolization. Transarterial embolization was performed with diluted glue (17-20\%) via the multiple feeding arteries 3 days later with the subsequent resolution of the EDAVFs. No neurological complication was observed. One patient experienced radiation dermatitis 1 week after the second embolization, which was conservatively treated. No other complications were observed. During the 2- to 17-month follow-up periods (average 10.7 months), symptoms completely resolved in two patients, markedly improved with residual mild paresthesia in two patients, and resolved to mild leg 


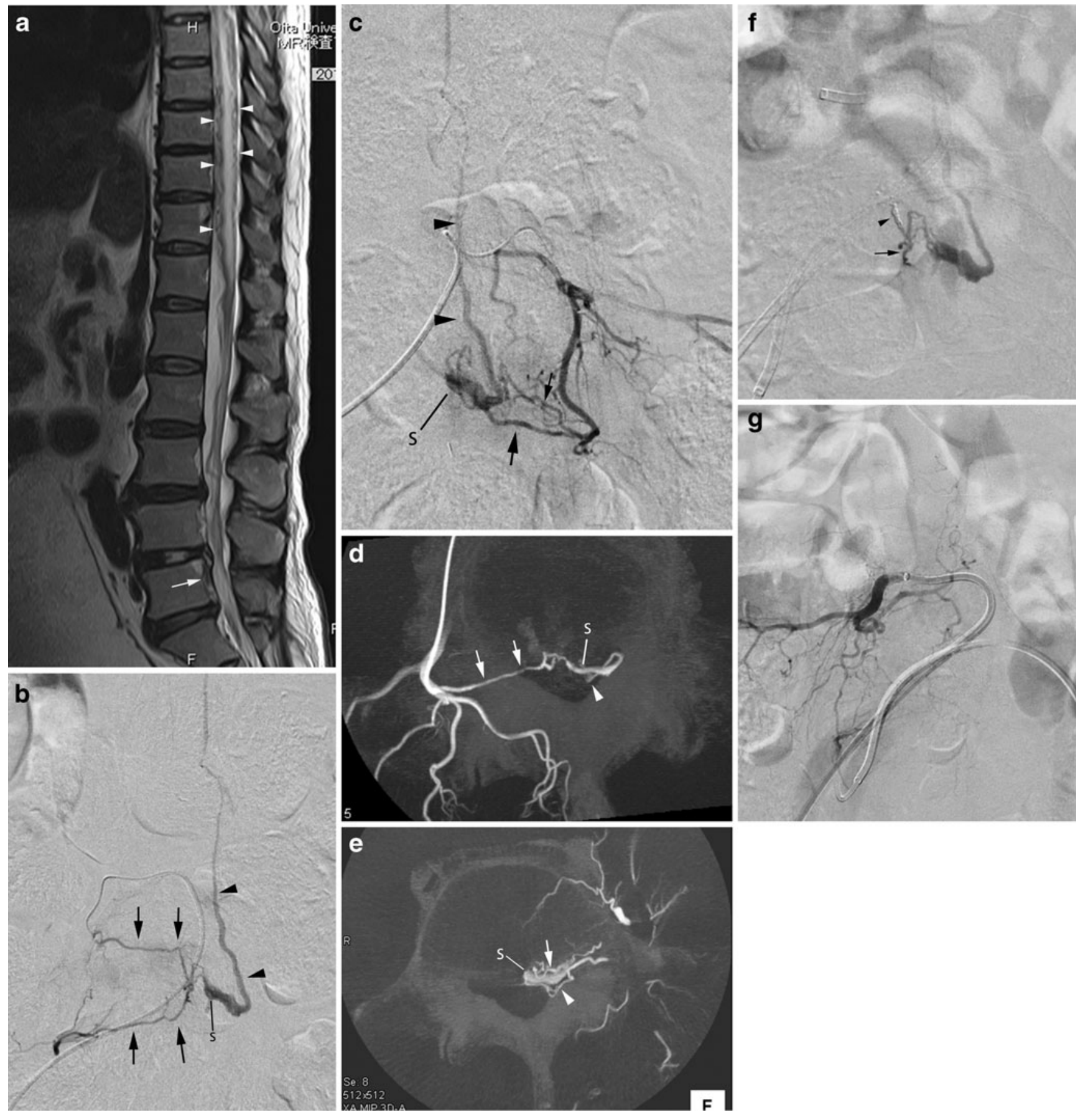

weakness in one patient. In the remaining one patient, who had presented with a history of 6 years of clinical symptoms, the symptoms slightly improved with residual paresthesia and leg weakness. A follow-up MRI showed either no or diminished high signal intensity in the spinal cord on $\mathrm{T} 2$-weighted images, with no findings suggesting residual/recurrent AVFs.

\section{Discussion}

Literature review

The PubMed and EMBASE databases and Google Scholar were searched for English-language publications of case series and case reports of spinal epidural arteriovenous 
Fig. 4 Case 5: a Sagittal T2-weighted MR images of the spine show a hyperintensity in the spinal cord and dilated vessels at the medullary surface (white arrowheads). A signal void (white arrow) suggesting a shunted pouch is seen in the ventral epidural space at L5. b Selective angiography of the dorsal somatic branch of the right $(R)$ fourth lumbar artery shows epidural AVFs with an epidural venous pouch $(S)$ draining into the left radiculomedullary/perimedullary vein (arrowheads). Retrograde filling of an additional feeder of the dorsal somatic branch of the right iliolumbar artery is also noted. Arrows indicate anastomosis of the dorsal somatic branches of the L4 and iliolumbar arteries. c Selective angiography of the left fourth lumber artery shows the epidural AVFs fed by a dorsal somatic branch (small arrow) and the radiculomeningeal artery (large arrow). These feeders shunted into the same venous pouch with multiple shunting points, and the AVFs drain into the left radiculomedullary/perimedullary vein (arrowheads). d Axial MIP image of the rotational angiography of the right fourth lumber artery demonstrates the AVF with a shunted venous pouch $(S)$ fed by the dorsal somatic branch (white arrows). The shunted venous pouch is located at the ventral epidural space and runs laterally towards the left and then continues to the radiculomedullary-perimedullary vein (arrowheads). e Axial MIP image from rotational angiography of the left fourth lumber artery shows AVFs fed by the dorsal somatic branch (white arrow) and the radiculomeningeal artery (white arrowheads) with multiple shunted points. $S$ : shunted venous pouch. f The dorsal somatic branch of the right fourth lumber artery was embolized with coils (arrowhead) just proximal to the retrocorporal anastomosis, and then a microcatheter (arrow) was advanced close to the fistulous portion via the right iliolumbar artery. A diluted glue $(20 \%$ NBCAlipiodol mixture) was injected via the microcatheter with simultaneous injection of $20 \%$ glucose via another microcatheter placed at the left dorsal somatic branch of the left fourth lumbar artery. g Selective angiography of the right fourth lumber artery after embolization shows disappearance of the AVFs

fistulas in January 2012, using the following terms in various combinations: arteriovenous fistulas, arteriovenous malformation, arteriovenous shunt, spinal, spine, extradural, epidural, paravertebral, and paraspinal. The reference lists of the retrieved articles were searched for additional reviews. Twentyfive reports with 64 patients were retrieved. After reviewing the 64 patients, the following 20 patients were excluded: 2 cases of paraspinal AVFs without epidural AV shunt, 6 cases of epidural AV shunts located in the dorsal epidural space (all presenting with an epidural hematoma), 3 cases of epidural AVFs of a large single hole fistula, and 6 infantile or child cases under 13 years of age, and 3 cases associated with arteriovenous malformations or neurofibromatosis. The 44 remaining patients with 45 ventral epidural AVFs in 20 published papers were further reviewed in detail [3-22] (Table 3). There were 30 males and 14 females, with ages ranging from 21 to 80 years (mean 63.9 years). The EDAVFs involved the cervical spine in 6 , thoracic spine in 6 , lumbar spine in 29 , sacrum in 2 , and sacrolumbar spine in 2 cases. The most common symptom was progressive myelopathy, which was encountered in 32 patients. Radiculopathy was observed in four patients, and both myelopathy and radiculopathy was found in six patients. One patient presented with a subarachnoid hemorrhage [22], and the other was incidentally found to
Table 3 Characteristics of 44 patients and 45 epidural arteriovenous fistulas in the literature review of 20 published papers

\begin{tabular}{ll} 
Characteristics & \\
\hline Gender & Male 31 \\
& Female 13 \\
Age (years) & $21-80$ (average 63.9) \\
Symptoms & Progressive myelopathy 31 \\
& Radiculopathy 4 \\
& Myelopathy and radiculopathy 7 \\
& Subarachnoid hemorrhage 1 \\
& No symptoms 2 \\
& Presence 5 (laminectomy 4, neck trauma 1) \\
& Absence 40 \\
History of trauma & Cervical spine 6 \\
& Thoracic spine 6 \\
Locations & Lumbar spine 29 \\
& Sacrolumbar spine 2 \\
& Sacrum 2 \\
& PM 14 \\
& PMPV 13 \\
& PV 12 \\
& No description 6
\end{tabular}

$P M$ perimedullary venous drainage, $P V$ paravertebral venous drainage, $P M P V$ perimedullary and paravertebral venous drainage

have an EDAVF but did not clinically manifest with any symptoms [20]. The time duration from the onset of clinical symptoms until treatment was noted in 31 patients, which varied from 1 day to 5 years (average 10 months). History of trauma was noted in five patients, which included previous surgery that included a laminectomy in four patients and neck trauma in one patient.

Regarding the angioarchitecture of EDAVF, feeding arteries were not described in seven cases. In the remaining 38 lesions, the EDAVFs were supplied by multiple feeding arteries from segmental arteries, including the intercostal artery, lumbar artery, lateral sacral artery, ascending/ deep cervical arteries, and vertebral arteries. In those reports, the authors reported that the AVF was supplied by radiculomeningeal branches in two cases, radiculomedullary artery in one case, bony and epidural branch in one case, and no detailed description in the other 34 cases. Some cases showed partial involvement of the vertebral body (osseous lesion). Draining veins were not described in 10 cases. In the remaining 35 lesions, the EDAVFs drained into the perimedullary vein alone in 14 cases, into the paravertebral veins in 8 cases, and into both perimedullary and paravertebral veins in 13 cases.

Among the 45 lesions reported, initial treatments were surgery $(n=16)$ and endovascular embolization $(n=29)$. The resolution of AVF was obtained in 9 of 16 lesions (56\%) 
with surgery and in 17 of 29 lesions (59\%) with endovascular embolization (Table 4). In the 29 lesions treated by endovascular embolization, 24 lesions were treated by transarterial embolization with Onyx $(n=14)$, glue $(n=9)$ or particles $(n=1)$. The remaining five lesions were treated by transvenous embolization alone $(n=3)$ or a combination of transarterial and transvenous embolization $(n=2)$. The rates of complete occlusion after transarterial embolization using Onyx and glue were 64 and $56 \%$, respectively. Complications were noted in two cases treated by transarterial embolization with Onyx, which were radiculopathy and trapping of a microcatheter. Table 5 described the relationship of the types of venous drainage of the AVFs with results of transarterial embolization. The types of venous drainage were mentioned in 19 of the 23 lesions treated by transarterial embolization by either Onyx or glue. There were 10 lesions with perimedullary drainage alone, 6 lesions with perimedullary and paravertebral drainage, and 4 lesions with paravertebral drainage alone. Complete obliteration of the AVF was obtained in 9 of the 10 lesions $(90 \%)$ with perimedullary drainage alone, in 2 of 6 lesions $(17 \%)$ with perimedullary and paravertebral drainage, and in 0 of 4 lesions $(0 \%)$ with paravertebral drainage alone. There are significant differences in the occlusion rates in each type of AVF drainage. Onyx was not found to be superior to glue for the complete obliteration of AVFs (3/9 in Onyx versus 8/11 in glue). Among the eight cases with paravertebral drainage and incomplete occlusion after transarterial embolization, three cases were treated by transvenous embolization, two cases were treated by surgery, and two cases were treated by transarterial embolization with a different embolic material. The clinical outcomes of the symptomatic patients were noted in 42 patients. Among them, symptoms disappeared in 16 patients, improved in 24 patients, and did not change in 2 patients.

\section{Characteristics of spinal ventral EDAVF}

Geibprasert et al. reported a new classification of dural AVFs according to craniospinal epidural venous anatomy. In their report, most of the dural/epidural AVFs belonged to

Table 4 Techniques and results of the initial treatment of 45 lesions

\begin{tabular}{lll}
\hline Techniques & $\begin{array}{l}\text { Disappearance of EDAVFs } \\
\text { by initial treatment }\end{array}$ \\
\hline $\begin{array}{l}\text { Endovascular } \\
\text { embolization }\end{array}$ & 29 & $17(59 \%)$ \\
TAE Glue 9, Onyx 14, particle 1 & 24 & 14 \\
TVE & 3 & 1 \\
$\quad$ Combined TAE and TVE & 2 & 2 \\
Surgery & 16 & $9(56 \%)$ \\
\hline
\end{tabular}

Table 5 Types of drainage veins and the results of transarterial embolization

\begin{tabular}{|c|c|c|c|}
\hline & $\begin{array}{l}\text { Drainage } \\
\text { type }\end{array}$ & $\begin{array}{l}\text { Disappearance } \\
\text { of AVFs }\end{array}$ & $\begin{array}{l}\text { Residual AVF } \\
\text { (further treatments) }\end{array}$ \\
\hline \multirow{3}{*}{$\begin{array}{l}\text { Glue } \\
\qquad(n=11)\end{array}$} & $\mathrm{PM}(7)$ & 7 & 0 \\
\hline & PMPV (2) & 1 & 1 (surgery) \\
\hline & PV (2) & 0 & 2 (TVE 1 , TAE with Onyx 1$)$ \\
\hline \multirow{3}{*}{$\begin{array}{l}\text { Onyx } \\
\qquad(n=\mathrm{g})\end{array}$} & $\mathrm{PM}(3)$ & 2 & 1 \\
\hline & PMPV (4) & 1 & 3 (TVE 1 , surgery 1 ) \\
\hline & PV (2) & 0 & $\begin{array}{l}2 \text { (TAE with glue } 1, \text { no } \\
\text { treatment } 1)\end{array}$ \\
\hline \multirow{3}{*}{$\begin{array}{l}\text { Totals } \\
\qquad(n=20)\end{array}$} & PM (10) & 9 & 1 \\
\hline & PMPV (6) & 2 & 4 (TVE 2 , surgery 2) \\
\hline & PV (4) & 0 & $\begin{array}{l}4(\mathrm{TVE} 1, \mathrm{TAE} 2, \text { no } \\
\text { treatment } 1)\end{array}$ \\
\hline
\end{tabular}

$P M$ perimedullary venous drainage, $P V$ paravertebral venous drainage, $P M P V$ perimedullary and paravertebral venous drainage

the ventral epidural group, and the ventral epidural group showed a female predominance, benign clinical presentations, and a lower rate of spinal (cortical) venous reflux. However, the actual number of cases of the spinal EDAVFs was not reported. The results of our cases and the literature review differ from their report. In reviewing the 50 cases, including our 6 cases and the 44 cases reported previously, there is a male predominance ( 35 males versus 15 females, $7: 3$ ), frequent symptoms of progressive myelopathy (37 of 50 patients, $74 \%$ ), and frequent spinal (perimedullary) venous drainage ( 33 of 45 lesions, $73 \%$ ). These data from our literature review cannot be directly compared with the analysis by Geibprasert et al. because asymptomatic cases could not be retrieved in our literature review. However, spinal EDAVFs may present with more aggressive clinical symptoms than are generally recognized.

Angioarchtecture and treatment options for spinal ventral EDAVF

Unlike spinal dural AVFs, ventral EDAVFs are located in the ventral epidural space, fed by multiple epidural branches and drain into the ventral epidural venous pouch. However, the feeding arterial branches have not been clearly described or have been incorrectly described in previous reports. In our six cases, dorsal somatic branches were the primary feeding branches to the EDAVFs, forming a shunted pouch located in the ventral epidural space. The ventral somatic branches also fed the EDAVF in two cases. These findings were clearly demonstrated by multiplanar reformatted images from rotational angiography without overlapping multiple vessels. These somatic branches supply the vertebral body. Therefore, some cases showed partial 
involvement of the vertebral body (osseous lesion) [4] The osseous lesions of spinal EDAVFs may be related to primary role of ventral epidural veins in vertebral venous drainage [2]. In our six cases, two cases fed by the ventral somatic branches showed bone erosions at the shunted pouch. The two cases showed larger size of shunted venous pouches and larger amount of shunt flow than the other four cases, these factors could cause the osseous lesion. Regarding the draining vein from the ventral EDAVFs, there were the following three types of drainage routes: the perimedullary venous drainage type (PM type), the paravertebral drainage type (PV type), and the combined perimedullary and paravertebral venous drainage type (PMPV type). In the PM type, the EDAVFs shunted to an epidural venous pouch and then drained through the radiculomedullary vein into the perimedullary vein. The PV-type AVFs drained via the radiculoemissary vein into paravertebral veins, such as the azygous vein and the ascending lumbar vein.

Regarding the treatment, some authors showed the clinical utility of transarterial embolization with Onyx. However, Onyx was not found to be superior to glue in our literature review. Successful results depend on the drainage types of the EDAVFs. The majority of the PM-type venous drainage cases could be successfully treated by transarterial embolization with either Onyx or glue. Additionally, PV and PMPV types were difficult to treat by transarterial embolization alone, and additional treatment by transvenous embolization was frequently required. Therefore, transvenous embolization or combined techniques of transarterial and transvenous embolization should be considered as a firstline treatment option for PV and PMPV types of EDAVFs.

Regarding clinical outcomes, complete recovery was obtained in only $37 \%$ of the patients, although most of the patients showed varying degrees of improvement of their symptoms. The improvements may be related to the reversibility of the spinal lesions caused by spinal venous congestion. Early treatment is required, because longstanding lesions could cause irreversible damage to the spinal cord. In our six cases, three cases were initially treated under incorrect diagnoses, such as disc herniation and demyelinating disease, at other hospitals. Therefore, the correct diagnosis, with careful assessment of the MR images at early periods of the disease, is also important for improvement in clinical outcomes.

In our experience, spinal ventral EDAVFs were mainly fed by the somatic branches, unlike spinal dural AVFs. With careful evaluation of their angioarchitecture, they can be successfully treated by transvenous coil embolization and/ or transarterial embolization with Onyx or glue.

Conflict of interest We declare that we have no conflict of interest.
Open Access This article is distributed under the terms of the Creative Commons Attribution License which permits any use, distribution, and reproduction in any medium, provided the original author(s) and the source are credited.

\section{References}

1. Patsalides A, Knopman J, Santillan A, Tsiouris AJ, Riina H, Gobin YP (2011) Endovascular treatment of spinal arteriovenous lesions: beyond the dural fistula. AJNR Am J Neuroradiol 32:798808

2. Geibprasert S, Pereira V, Krings T et al (2008) Dural arteriovenous shunts: a new classification of craniospinal epidural venous anatomical bases and clinical correlations. Stroke 39:2783-2794

3. Silva N Jr, Januel AC, Tall P, Cognard C (2007) Spinal epidural arteriovenous fistulas associated with progressive myelopathy. Report of four cases. J Neurosurg Spine 6:552-558

4. Suh DC, Choi CG, Sung KB et al (2004) Spinal osseous epidural arteriovenous fistula with multiple small arterial feeders converging to a round fistular nidus as a target of venous approach. AJNR Am J Neuroradiol 25:69-73

5. Goyal M, Willinsky R, Montanera W, terBrugge K (1999) Paravertebral arteriovenous malformations with epidural drainage: clinical spectrum, imaging features, and results of treatment. AJNR Am J Neuroradiol 20:749-755

6. Braun JRV (2007) Spinal arteriovenous epidural fistula with acute paraplegia. Interv Neuroradiol 13:75-78

7. Lim SM, Choi IS (2009) Spinal epidural arteriovenous fistula: a unique pathway into the perimedullary vein. Interv Neuroradiol 15:466-469

8. Krings T, Mull M, Bostroem A et al (2006) Spinal epiduralarteriovenous fistula with perimedullary drainage. Case report and pathomechanical considerations. J Neurosurg Spine $5: 353-358$

9. Pirouzmand F, Wallace MC, Willinsky R (1997) Spinal epidural arteriovenous fistula with intramedullary reflux. J Neurosurg $87: 633-635$

10. Kawabori M, Hida K, Yano S, Asano T, Iwasaki Y (2009) Cervical epidural arteriovenous fistula with radiculopathy mimicking cervical spondylosis. Neuro Med Chir (Tokyo) 49:108-103

11. Clarke MJ, Patrick TA, White JB (2009) Spinal extradural arteriovenous malformations with parenchymal drainage: venous drainage variability and implications in clinical manifestations. Neurosurg Focus 26:E5

12. Khaldi A, Hacein-Bey L, Origitano TC (2009) Spinal epidural arteriovenous fistula with late onset perimedullary venous hypertension after lumbar surgery: case report and discussion of the pathophysiology. Spine 34:775-779

13. Marshman LA, David KM, Chawda SJ (2007) Lumbar extradural arteriovenous malformation: case report and literature review. Spine J 7:374-379

14. Lanzino G, D’urso PI, Kallmes DF, Cloft HJ (2012) Onyx embolization of extradural spinal arteriovenous malformations with intradural venous drainage. Neurosurgery 70:329-333

15. Heier HA, Lee BC (1987) A dural spinal arteriovenous malformation with epidural venous drainage: a case report. AJNR Am J Neuroradiol 8:561-563

16. Willinsky R, terBrugge K, Montanera W, Wallace MC, Gentili F (1993) Spinal epidural arteriovenous fistulas: arterial and venous approaches to embolization. AJNR Am J Neuroradiol $14: 812-817$ 
17. Arnaud O, Bille E, Pouget J, Serratrice G, Salamon G (1994) Epidural arteriovenous fistula with perimedullary venous drainage: case report. Neuroradiology 36:490-449

18. Matsumura A, Tsuboi K, Hyodo A, Yoshizawa K, Nose T (1986) Lumbosacral extradural spinal arteriovenous malformation with blood supply from branches of internal iliac arteries. Neurochirurgia 29:235-257

19. Sharma RR, Selmi F, Cast IP, O'Brien C (1994) Spinal extradural arteriovenous malformation presenting with recurrent hemorrhage and intermittent paraplegia: case report and review of the literature. Surg Neurol 42:26-31
20. Rangel-Castilla L, Holman PJ, Krishna C, Trask TW, Klucznik RP, Diaz OM (2011) Spinal extradural arteriovenous fistulas: a clinical and radiological description of different types and their novel treatment with Onyx. J Neurosurg Spine 15:541549

21. Asai J, Hayashi T, Fujimoto T, Suzuki R (2001) Exclusively epidural arteriovenous fistula in the cervical spine with spinal cord symptoms: case report. Neurosurgery 48:1372-1376

22. Hemphill JC III, Smith WS, Halbach VV (1998) Neurologic manifestation of spinal epidural arteriovenous malformation. Neurology $50: 817-819$ 